\title{
Mary Lyon and the hypothesis of random X chromosome inactivation
}

\author{
Peter S. Harper
}

Published online: 5 June 2011

(C) Springer-Verlag 2011

\begin{abstract}
The 50th anniversary of Mary Lyon's 1961 Nature paper, proposing random inactivation in early embryonic life of one of the two $\mathrm{X}$ chromosomes in the cells of mammalian females, provides an opportunity to remember and celebrate the work of those involved. While the hypothesis was initially put forward by Lyon based on findings in the mouse, it was founded on earlier studies, notably the work of Susumu Ohno; it was also suggested independently by Beutler and colleagues using experimental evidence from a human X-linked disorder, glucose-6phosphate dehydrogenase deficiency, and has proved to be of as great importance for human and medical genetics as it has for general mammalian genetics. Alongside the hypothesis itself, previous cytological studies of mouse and human chromosomes, and the observations on X-linked mutants in both species deserve recognition for their essential role in underpinning the hypothesis of random X-inactivation, while subsequent research on the $\mathrm{X}$-inactivation centre and the molecular mechanisms underlying the inactivation process represent some of the most outstanding contributions to human and wider mammalian genetics over the past 50 years.
\end{abstract}

\section{Introduction}

If one were asked to choose an area of science and medicine that best epitomises the close and fruitful links between basic genetic research, medical genetics and wider clinical medicine, one could do no better than to take the

\section{P. S. Harper $(\bowtie)$}

Institute of Medical Genetics, School of Medicine,

Cardiff University, Cardiff, UK

e-mail: HarperPS@ cardiff.ac.uk topic of X-inactivation, which has provided some of the most important and medically relevant advances of the past half century, with the promise of more to come in the future. From the time of Mary Lyon's first proposal of the hypothesis bearing her name, 50 years ago (Lyon 1961), basic experimental research, notably on the mouse, and observations on humans with chromosomal defects and other X-linked mutational disorders have mutually supported each other, and $\mathrm{X}$-inactivation has become pivotal to the entire field of human genetics.

Lyon's 1961 paper, as is almost always the case with major unifying hypotheses, was not the beginning of research in this area, but brought together earlier work whose significance had not been fully recognised and provided opportunities for further experimental and clinical studies in both basic developmental biology and more clinical genetics. It is thus thoroughly appropriate that her contributions are chosen as the focal point for this collection of papers marking the first 50 years of X-inactivation research, though equally noting that a series of other talented workers have made key contributions during this period, and indeed before it.

\section{Mary Lyon: a brief biography}

Born in 1925 at Norwich, England, Mary Frances Lyon decided to make a career in science after being inspired by a teacher at school; none of her immediate family had a scientific or medical background. She studied at Cambridge University, graduating in 1946 (although women were not allowed to be awarded official degrees at Cambridge until 1948). She was already clear at this point that developmental biology was her main area of interest; but university life and teaching were badly disrupted at the time by the World 
War, and $\mathrm{CH}$ Waddington, pioneer of developmental genetics, was away from Cambridge on war work.

She continued at Cambridge for her $\mathrm{PhD}$, awarded in 1950, studying with the eminent theoretical geneticist RA Fisher and working on the mouse mutant pallid, as part of his pioneering gene mapping project. However, she was not entirely happy with either Fisher or the lack of facilities for experimental work (see interviews with her in 2005 in Harper 2010 and also Gitschier 2010), and next moved to Edinburgh, where Waddington had now begun a programme of genetic and radiobiological research under the Medical Research Council. Here she began research, initially with Douglas Falconer, on the recently discovered X-linked mouse traits, some naturally occurring, others radiation induced, work that would lead directly to the concept of X-inactivation. She considers this to have been the happiest part of her career.

In 1955 , a policy decision was taken to move the mouse genetics research group, under TC Carter, as a whole to Harwell, Oxfordshire, where most of the MRC's radiation biology research was centred. Mary Lyon moved with the group and has remained there ever since, being director of the genetics section between 1962 and 1986 and continuing actively after her official retirement in 1990 (compulsory then at age 65) up to the present. Other contemporaries among the outstanding and closely interacting Harwell group of mammalian geneticists include Anthony Searle, Bruce Cattanach and cytogeneticist Charles Ford. A picture of the work and environment of the Harwell unit can be gained from Lyon's obituary of Charles Ford (Lyon 2001).

\section{Background to $\mathrm{X}$-inactivation}

The mammalian $\mathrm{X}$ chromosome had been the subject of considerable research interest for more than a decade before Mary Lyon's proposal of random X chromosome inactivation, and her hypothesis drew extensively from this earlier work. There was a particular need for some hypothesis that could satisfactorily explain why there was not harmful excess expression of most $\mathrm{X}$-linked genes in females as a result of their having two $X$ chromosomes by comparison to the single $\mathrm{X}$ of males, in other words, a mechanism for what was termed 'dosage compensation'. There were two principal strands of evidence already existing by the end of the 1950s: cytological observations of the $\mathrm{X}$ chromosome, in both mouse and humans, and phenotypic studies of females heterozygous for X-linked mutant traits, or with sex chromosome abnormalities, again in both species.

Cytological research on mammalian chromosomes was severely hampered until the 1950 s by technological limitations, and by their small size and large number in compari- son with invertebrate chromosomes, so that most of the concepts regarding function of the sex chromosomes, notably in relation to sex determination, were still based on the much earlier studies of Drosophila and other insects, by Stevens (1905), Wilson $(1905,1911)$ and other pioneers. For Drosophila, in particular, the number of $\mathrm{X}$ chromosomes, rather than any role of the Y chromosome, was considered to be the principal factor in sex determination, and for half a century it was assumed that this applied also to mammals, including humans.

One of the first major advances, entirely serendipitous, was the recognition in 1949 of the sex chromatin body in the cells of most female mammals, including humans, the original discovery being made by Ewart (Mike) Bertram, working with Murray Barr, both primarily neuroanatomists, in London, Ontario (Barr and Bertram 1949). It was soon recognised that this body was related to the $\mathrm{X}$ chromosome, and its simple detection by the use of buccal smears made it a valuable diagnostic tool in the investigation of human intersexual states at a time when detailed chromosome analysis was still impossible. The early research on the sex chromatin is well brought together in the book of Keith Moore, The Sex Chromatin (Moore 1966a), including a first-hand historical account of the discovery (Moore 1966b). An interview with Mike Bertram and Keith Moore by the author is available on the website of the Genetics and Medicine Historical Network (http://www.genmedhist.org/ interviews). Our understanding was further advanced by the cytological and theoretical studies of Susumo Ohno, which laid most of the foundations of modern sex chromosome biology. This information is synthesised most clearly in his monographs, published later, notably his Sex Chromosomes and Sex Linked Genes (Ohno 1967), in which he also formulated his hypothesis of the evolutionary conservation of $\mathrm{X}$-linked genes, often known as 'Ohno's law'. Most relevant to $\mathrm{X}$-inactivation was his observation that in the female rat (Ohno et al. 1959) and mouse (Ohno and Hauschka 1960), one X chromosome was condensed and heteropyknotic, contrasting with the other which was uncondensed and similar in character to the autosomes. This, along with the finding by others of humans with intersexual disorders showing multiple sex chromatin bodies (see Moore 1966a), led to the suggestion that only one X chromosome in the mammalian female cell was active, the observed heteropyknotic X (or X's) being inactive and representing the sex chromatin body.

The phenotypic observations that provided background evidence for Mary Lyon's hypothesis were also partly human, partly from the mouse. Notable among the first category were Paul Polani's studies of patients with Turner syndrome (Polani et al. 1954, 1956), where he showed that, despite their female phenotype, they had a male frequency of colour blindness, suggesting presence 
of a single $\mathrm{X}$ chromosome, while there was likewise an absence of sex chromatin; in 1959 a full chromosome study by Charles Ford (a close colleague at Harwell of Mary Lyon), Polani and colleagues confirmed that these patients were indeed $45 \mathrm{XO}$ in their chromosome constitution, showing that presence of a Y chromosome was necessary for a male phenotype and that mammalian sex determination was unlike that of Drosophila; in the same year, the XO mouse was shown to be fully fertile (unlike human Turner syndrome) and of normal phenotype (Welshons and Russell 1959).

Also in 1959, it was found by Jacobs and Strong that patients with Klinefelter syndrome, showing a male phenotype, but with infertility, had an XXY chromosome constitution, complementing the evidence from the XO Turner syndrome and showing that male determination was a function of the $\mathrm{Y}$ chromosome.

Further phenotypic evidence came from studies by Mary Lyon and others (Dickie 1954; Lyon 1960) on various mouse X chromosome mutants, such as tortoiseshell, mottled, brindled and tabby, which showed a variegated or mottled appearance in heterozygous females. Also on record at this point, though their significance was still largely unrecognised, were reports of similar "mosaic" patterning in human females heterozygous for X-linked disorders, particularly eye and skin conditions where these features were readily visible (see Lyon 1962 and the monograph of McKusick 1964, both discussed below, for primary references to these reports).

\section{The "Lyon hypothesis"}

Mary Lyon published her hypothesis as a brief report to Nature in April 1961, which makes no mention of Homo sapiens. The paper gave no new original experimental findings, but brought together the various lines of evidence mentioned above and provided a unifying hypothesis to explain them, which has stood the test of time to a remarkable degree.

The key elements of the hypothesis were first, that each cell of a female mammal had only one active X chromosome and that the observed heteropyknotic $\mathrm{X}$ was the inactive one; second, that this inactivation occurred in early embryonic life; and third, that the inactivated $\mathrm{X}$ of a particular cell might be of either maternal or paternal origin, and that this was randomly determined. All descendants of a particular cell line would reflect the inactivation of the parent cell, so that females would be mosaic in respect of their $\mathrm{X}$ chromosome constitution, corresponding to the observed variegated phenotype.

In her Nature paper Lyon clearly distinguished the different potential effects on phenotype depending on whether the particular gene had a local or a more remote action; in the latter case the presence of some cells with a normal "wild type" X active might result in a normal phenotype.

This brief paper was followed by a fuller development of the hypothesis (Lyon 1962), especially focusing on human X-linked conditions, which appeared in the American Journal of Human Genetics (submitted August 1961, published June 1962). Mary Lyon says that she had put forward her hypothesis initially entirely on the evidence from the mouse, but that subsequently she had given considerable thought to its more universal application in mammals, including humans (interview; Gitschier 2010). This may well have been partly as a result of discussions with colleagues, including human geneticists, both at Harwell and in Oxford, where she presented the work at an informal discussion group, and where her Harwell colleague Charles Ford had also made links in relation to his human chromosome studies.

This second paper contains an extensive table, based largely on the human genetics and medical literature, giving details on 16 human X-linked conditions, for many of which some "mottled" features similar to those seen in the mouse mutants had been observed and reported. This was particularly the case for X-linked disorders involving the eye (e.g. choroideraemia, retinitis pigmentosa) and skin (e.g. anhidrotic ectodermal dysplasia). For all the conditions listed, there was variable expression found in heterozygotes, which supported random inactivation of one $\mathrm{X}$ chromosome as proposed in the hypothesis. This paper also discusses the recent findings in human sex chromosome anomalies and concludes that they also support X-inactivation, though noting that the presence of phenotypic abnormalities in human Turner syndrome, in contrast to the XO mouse, must suggest either that some X-linked loci escape complete inactivation, or that these abnormalities might be determined before $\mathrm{X}$-inactivation occurs.

Taken together, these two papers provide a clear and detailed statement of Lyon's X-inactivation hypothesis, together with a considerable amount of evidence that both tests it and mostly supports it. In fact most of the scientific community were prepared to accept it rapidly, perhaps largely because it was so consistent with the new emerging findings both in the mouse and human regarding the function of the sex chromosomes, as well as solving the long standing problem of dosage compensation. The only prominent sceptic in the field seems to have been the mouse geneticist Hans Grueneberg; in interview (Gitschier 2010), Mary Lyon suggests that he may have been reluctant to believe that a major biological hypothesis could have come from a woman!

\section{Confirmation and development of the hypothesis}

Given how clearly the hypothesis of random X chromosome inactivation followed from both experimental $\mathrm{X}$ chromosome 
studies in the mouse and clinical data in humans that were already on the record, it would be surprising if other workers had not already been thinking along the same lines as Mary Lyon. In fact her American mouse geneticist colleague Liane Russell simultaneously published the suggestion that only one chromosome in a female cell was active (Russell and Bangham 1961; Russell 1961).

A fuller independent, though not simultaneous, statement of the hypothesis was given by Beutler et al. (1962). Beutler, a haematologist, was working at City of Hope Hospital, Duarte, California, where Susumo Ohno was also based; hence, Beutler had ample opportunity to think of how Ohno's work might be applied to X-linked disorders in his own field of blood disease and acknowledges their fruitful discussions. He has also written a biographical memoir of Ohno (Beutler 2002) that illustrates Ohno's key role in the whole field of $\mathrm{X}$ chromosome biology and the inspiration that he provided for other workers in this community and more widely. In contrast to Mary Lyon's initial formulation of her hypothesis in terms of the mouse, with no mention of human evidence, Beutler et al.'s paper is based on experimental studies of the human X-linked disorder glucose-6-phosphate dehydrogenase (G6PD) deficiency, for which they showed biochemical evidence suggesting two separate populations of red blood cells in heterozygous females. On the basis of this they proposed, as had Lyon, random $\mathrm{X}$ chromosome inactivation.

Since Lyon's Nature paper had already appeared by the time that Beutler et al.'s paper was submitted to the Proceedings of the National Academy of Sciences (November 1961) and is cited in it, it is difficult to be sure which elements of the Beutler paper were totally independent, but clearly the experimental work was, while both papers owe and acknowledge a debt to the work and ideas of Susumo Ohno. The fact that the papers came from completely different origins, Lyon's from mouse genetics, Beutler's from human inherited disease, was undoubtedly a major factor in the early acceptance of both the correctness and the general applicability of the hypothesis. Proof at the cellular level soon also came from G6PD, with Davidson et al. (1963) showing only one type of G6PD in clones of cultured cells derived from heterozygous females. Beutler (2008) has provided a general historical account of G6PD deficiency and the insights that it has provided.

From the viewpoint of human and medical geneticists, the concept of $\mathrm{X}$-inactivation rapidly became central to our understanding of $\mathrm{X}$-linked disease and to such practical aspects as carrier detection and genetic counselling. This integration with the rest of our knowledge can be clearly seen in the remarkable early (1964) monograph of Victor McKusick, On the X Chromosome of Man, which formed the starting point for his later catalogue, Mendelian Inheritance in Man (first edition 1966), and which contains details of all human $\mathrm{X}$-linked disorders known at the time, as well as a general account of $\mathrm{X}$ chromosome biology.

During the 50 years since 1961, our understanding of the extent, the timing, the evolution among mammals and the underlying mechanisms of $\mathrm{X}$-inactivation has progressively resolved many of the uncertainties involved; it has remained an area to which Mary Lyon herself has continued to contribute, while her historical reviews, notably her Allan Award lecture (Lyon 1988) and other reviews (Lyon 1992, 2002a, b), give a vivid picture of how the field has developed, as do the papers in this special issue of Human Genetics. Notable areas of advance include the identification and molecular analysis of the $\mathrm{X}$-inactivation centre, the role of methylation in X-inactivation, and the patterns of development of the sex chromosomes and of $\mathrm{X}$-inactivation in monotremes and marsupials. The clearest overall account of the field, especially in relation to the importance of $\mathrm{X}$-inactivation to sex differences in human health, is Barbara Migeon's (2007) book, Females are Mosaics.

Although the development of our understanding of $\mathrm{X}$-inactivation in recent years is best followed in these individual articles on different aspects, some of these advances are so important that they need a brief note here:

Timing of $X$-inactivation was recognised from the beginning to be a major question by Lyon and others, but they would certainly be surprised by how early and how complex the process has proved to be (see Payer et al. 2011; Van den Berg et al. 2011, in this issue). The inactivation of the paternal $\mathrm{X}$ chromosome at the pre-implantation stage, the continuation of this in extra-embryonic tissue, and the reactivation in the embryo itself, with subsequent random $\mathrm{X}$-inactivation, are only now becoming clear.

The extent of X-inactivation and the exceptions to it have likewise provided both solutions and surprises. Lyon herself recognised that there must be such exceptions, at least in humans where infertility and a range of other phenotypic defects are found in such conditions as Turner syndrome that would not be expected if the second $\mathrm{X}$ were totally inactive. Discovery and demarcation of the pseudo-autosomal regions at the tips of the $\mathrm{X}$ chromosome and of other genes escaping $\mathrm{X}$-inactivation has given an increasingly clear picture of these that has been helped by the availability of the complete $\mathrm{X}$ chromosome gene map and DNA sequence.

The role of the X-inactivation centre and of its key gene Xist likewise provide a remarkable story in their own right (see Pontier and Gribnau 2011; Brockdorff and Tattermusch 2011; Arthold et al. 2011, and other articles in this issue). The remarkable expression of this gene solely in cis (Brown et al. 1991) and the role of methylation in the spread of inactivation are findings that could not have been anticipated at the time when the Lyon hypothesis was first proposed. 
The evolution of $X$-inactivation in mammals, particularly the stages seen in monotremes and marsupials by comparison with reptiles and with later placental mammals, are both fascinating in their own right and important evidence in the general evolution of these major groups (Graves 1996).

Finally, the relevance of $\mathrm{X}$-inactivation to human genetic disease and to wider sex differences in human health has proved to be of major significance. Lyon's (1961) second paper recognised this in relation to human $\mathrm{X}$-linked disorders, while studies of structural X chromosome abnormalities translocations as well as numerical abnormalities formed a key foundation for modern concepts of mammalian sex determination and subsequently for fine mapping of the pseudoautosomal regions (see Yang et al. 2011, in this issue for details) and a range of important X-linked disease genes. But the wider role of X-inactivation in the overall health differences between the sexes, notably the greater vulnerability of males in almost all areas of illness, has not yet been fully explored, as emphasised by Migeon (2007) in her book. There is indeed a major amount of research still to be done before we understand this, which will remain to be resolved even when the underlying mechanisms of X-inactivation have been more fully worked out.

\section{Conclusion}

The value of any hypothesis can be judged to a large extent by the insights it generates into the field as a whole, more than by its absolute "correctness". In this respect Mary Lyon's hypothesis has been outstanding, underlying and stimulating such concepts as the pseudoautosomal regions, the X-inactivation centre and the gene XIST, the role of methylation and the function of heterochromatin, among others. Likewise, the exceptions to the hypothesis have proved as valuable as the factors supporting it.

While many workers have contributed to our understanding of $\mathrm{X}$-inactivation over the past 50 years, the original contributions of Mary Lyon herself remain the foundation on which all subsequent progress has been based.

\section{References}

Arthold S, Kurowski A, Wutz A (2011) Mechanistic insights into chromosome-wide silencing in $\mathrm{X}$ inactivation. Hum Genet. doi:10.1007/s00439-011-1002-0

Barr ML, Bertram EG (1949) A morphological distinction between the neurones of the male and female, and the behaviour of the nucleolar satellite during accelerated nucleoprotein synthesis. Nature 163:676-677
Beutler E (2002) Susumu Ohno 1928-2000. Biographical memoirs, vol 81. The National Academy Press, Washington, DC

Beutler E (2008) Glucose-6-phosphate dehydrogenase deficiency: a historical perspective. Blood 111:16-24

Beutler E, Yeh M, Fairbanks VF (1962) The normal human female as a mosaic of X-chromosome activity: studies using the gene for G-6-PD-deficiency as a marker. Proc Natl Acad Sci USA 48:9-16

Brockdorff N, Tattermusch A (2011) A scaffold for X chromosome inactivation. Hum Genet. doi:10.1007/s00439-011-1027-4

Brown CJ, Ballabio A, Rupert JL, Grompe M, Tonloranzi R, Willard HF (1991) A gene from the region of the human X inactivation centre is expressed exclusively from the inactive $\mathrm{X}$ chromosome. Nature 349:38-44

Davidson RG, Nitowsky HM, Childs B (1963) Demonstration of two populations of cells in the human female heterozygous for glucose-6-phosphate dehydrogenase variants. Proc Natl Acad Sci USA 50:481-485

Dickie MM (1954) The tortoiseshell house mouse. J Hered 45:158-159

Ford CE, Jones KW, Polani PE, de Almeida JC, Briggs JH (1959) A sex chromosome anomaly in a case of gonadal dysgenesis (Turner's syndrome). Lancet 1:711-713

Gitschier J (2010) The gift of observation: an interview with Mary Lyon. PLoS Genet 6(1):e1000813. doi:10.1371/journal.pgen.1000813

Graves JAM (1996) Mammals that break the rules: genetics of marsupials and monotremes. Ann Rev Genet 30:233-260

Harper PS (2010) Interview with Mary Lyon, 2005. http://www. genmedhist.org/interviews

Jacobs PA, Strong JA (1959) A case of human intersexuality having a possible XXY sex-determining mechanism. Nature 183:302-303

Lyon MF (1960) A further mutation of the mottled type in the house mouse. J Hered 51:116-121

Lyon MF (1961) Gene action in the X-chromosome of the mouse (Mus musculus L.). Nature 190:372-373

Lyon MF (1962) Sex chromatin and gene action in the mammalian X-chromosome. Am J Hum Genet 14:135-148

Lyon MF (1988) The William Allan Memorial Award Address: Xchromosome inactivation and the location and expression of $\mathrm{X}$ linked genes. Am J Hum Genet 42:8-16

Lyon MF (1992) Some milestones in the history of X-chromosome inactivation. Annu Rev Genet 26:17-28

Lyon MF (2001) Charles Edmond Ford, 24 October 1912-7th January 1999. Biog Mems Fell R Soc Lond 47:189-201

Lyon MF (2002a) A personal history of the mouse genome. Annu Rev Genomics Hum Genet 3:1-16

Lyon MF (2002b) X-chromosome inactivation and human genetic disease. Acta Paediatr Suppl 439:107-112

McKusick VA (1964) On the X chromosome of man. American Institute of Biological Sciences, Washington, DC

McKusick VA (1966) Mendelian inheritance in man: catalogs of autosomal dominant, autosomal recessive, and X-linked phenotypes, 1 st edn. The Johns Hopkins University Press, Baltimore

Migeon BR (2007) Females are mosaics. X inactivation and sex differences in disease. Oxford University Press, New York

Moore KL (ed) (1966a) The sex chromatin. WB Saunders, Philadelphia

Moore KL (ed) (1966b) The discovery of the sex chromatin. In: The sex chromatin. WB Saunders, Philadelphia, pp 7-15

Ohno S (1967) Sex chromosomes and sex-linked genes. Springer, New York

Ohno S, Hauschka TS (1960) Allocycly of the X-chromosome in tumors and normal tissues. Cancer Res 20:541-545

Ohno S, Kaplan WD, Kinosita R (1959) Formation of the sex chromatin by a single X-chromosome in liver cells of Rattus norwegicus. Exp Res 18:415-418

Payer B, Lee JT, Namekawa SH (2011) X-inactivation and X-reactivation: epigenetic hallmarks of mammalian reproduction and pluripotent stem cells. Hum Genet. doi:10.1007/s00439-011-1024-7 
Polani PE, Hunter JF, Lennox B (1954) Chromosomal sex in Turner's syndrome with coarctation of the aorta. Lancet 2:120-121

Polani PE, Lessof MH, Bishop PMF (1956) Colour blindness in ovarian agenesis (gonadal dysplasia). Lancet 271:118-120

Pontier DB, Gribnau J (2011) Xist regulation and function explored. Hum Genet. doi:10.1007/s00439-011-1008-7

Russell LB (1961) Genetics and mammalian sex chromosomes. Science 133:1795-1803

Russell LB, Bangham JW (1961) Variegated-type position effects in the mouse. Genetics 46:509-525

Stevens NM (1905) Studies in spermatogenesis with especial reference to the accessory chromosome. Carnegie Institute of Washington, publication number 6
Van den Berg IM, Galjaard R-JH, Laven J, Van Doornik JH (2011) $\mathrm{XCI}$ in early mouse and human embryos: first there is remodelling. Hum Genet. doi:10.1007/s00439-011-1014-9

Welshons WJ, Russell LB (1959) The Y-chromosome as the bearer of male determining factors in the mouse. Proc Natl Acad Sci USA 45:560-566

Wilson EB (1905) Studies on chromosomes. The behaviour of the idiochromosomes in Hemiptera. J Exp Zool 2:371-405

Wilson EB (1911) The sex chromosomes. Mikrosk Anat Entwicklungsmech 77:249-271

Yang C, Chapman A, Kelsey A, Minks J, Cotton A, Brown C (2011) $\mathrm{X}$-chromosome inactivation: molecular mechanisms from the human perspective. Hum Genet. doi:10.1007/s00439-011-0994-9 